Research Article

\title{
Study on the Rheological Properties and Constitutive Model of Shenzhen Mucky Soft Soil
}

\author{
Huang Wei ${ }^{1,2}$, Liu Dong-yan ${ }^{3,1,2}$, Zhao Bao-yun ${ }^{3,}$, Feng Yan-bo ${ }^{1,2}$ and Xia Yu-chao ${ }^{4}$ \\ ${ }^{1}$ College of Civil Engineering, Chongqing University, 400045, Chongqing, China \\ ${ }^{2}$ Key Laboratory of New Technology for Construction of Cities in Mountain Area (Chongqing University) Ministry of Education, \\ 400045, Chongqing, China \\ ${ }^{3}$ School of Civil Engineering and Architecture, Chongqing University of Science \& Technology Chongqing, 401331, Chongqing, China \\ ${ }^{4}$ Mechanical and Construction Engineering, Northumbria University, United Kingdom
}

Received 10 February 2014; Accepted 23 July 2014

\begin{abstract}
In order to obtain the basic parameters of numerical analysis about the time-space effect of the deformation occurring in Shenzhen deep soft-soil foundation pit, a series of triaxial consolidated-undrained shear rheology tests on the peripheral mucky soft soil of a deep foundation pit support were performed under different confining pressures. The relations between the axial strain of the soil and time, as well as between the pore-water pressure of the soil and time, were achieved, meanwhile on the basis of analyzing the rheological properties of the soil, the relevant rheological models were built. Analysis results were proved that the rheology of Shenzhen mucky soft soil was generally viscous, elastic, and plastic, and had a low yield stress between 90 and $150 \mathrm{kPa}$. The increase in pore-water pressure made the rheological time effect of the mucky soft soil more remarkable. Thus, the drainage performance in practical engineering should be improved to its maximum possibility extent to decrease the soft-soil rheological deformation. Lastly, a six-component extended Burgers model was employed to fit the test results and the parameters of the model were determined. Findings showed that the extended Burgers model could satisfactorily simulate the various rheological stages of the mucky soft soil. The constitutive model and the determination of its parameters can be served as a foundation for the time-space effect analysis on the deformation of deep soft-soil foundation pits.
\end{abstract}

Keywords: Shenzhen mucky soft soil; rheological property; constitutive model; triaxial consolidated-undrained shear rheology test.

\section{Introduction}

Shenzhen, a coastal city with a long coastline in southern China, has a wide distribution of under-consolidated and normally consolidated mucky soft soil $[1,2,3]$ that was deposited in the Quaternary Period. Given its unique depositional environment, Shenzhen mucky soft soil has a complex composition, a flocculent microstructure, which results in a different mechanical effect from other regular cohesive soils (e.g., high sensitivity, high compressibility, and prominent rheological property) $[4,5,6]$.

Soft-soil deformation is not only related to the load (deviator stress $q$ ) but also the loading time. The variation in soft-soil stress and strain with time is called the rheological property, which includes, in the broad sense, creep, stress relaxation, long-term strength, elastic aftereffect, and hysteresis effect [7]. Modern engineering has increasingly strict requirements on long-term deformation of soft-soil foundations after construction. Thus, the deformation time effect of projects based on soft-soil foundations, including urban foundation pit projects excavated under complex softsoil geological environments, has drawn more and more attention. Post-excavation monitoring data indicate that deep foundation pit projects excavated based on soft-soil

*E-mail address: baoyun666@163.com ISSN: 1791-2377 @ 2014 Kavala Institute of Technology. All rights reserved. foundations possess remarkable time-space effects [8, 9]. Scientific research and engineering practice prove that the main cause of the time-space effect of deep foundation pit deformation is the rheological property of soft soils $[10,11]$. Therefore, building a constructive model that accurately reflects the practical rheological properties of mucky soft soil is a key factor in study of the time-space effect of softsoil foundation pit deformation. The approach by determining relevant parameters of the constructive model according to rheological test results and applying them to the modeling of deep soft soil foundation pits and to the numerical analysis of the time-space effect can be an effective way to deal with the complex rheological properties of mucky soft soil.

Given the strong regionalism of soft soil deformation, the rheological properties of soft soil vary greatly with depositional environments and grain composition. The widely distributed mucky soft soil of Shenzhen deposited in the Quaternary Period has a thickness of $2 \mathrm{~m}$ to $15 \mathrm{~m}$. A foundation pit project excavated based on the soft-soil foundation in Shenzhen can easily result in engineering accidents because of the excessive deformation gradually formed with time. Lacking of timely support and protection after the foundation excavation, a large-scale collapse occurred at Shenzhen Metro Line No. 5 in August 2010 because of the excessive deformation of the enclosure structure. The accident, which damaged roads around the 
deep foundation pit and resulted in casualties, had a great influence in society. Thus, this event has great practical significance on the prediction and control of the deformation of deep foundation pits to strengthen the research on timespace effect of deep foundation pits. Zhang [12] and Gao [13] conducted studies on the rheological properties of Henan and Shanghai clay and applied their research results to the time-space effect analysis of foundation pit deformation. They concluded that foundation pit analysis based on soil body rheological properties can better meet the requirements of practical projects than elasticity theory only. Bo M W [14] and Chen [15] have also made research achievements in the relation between soft-soil deformation and rheology. Liu [16] performed a systematic study on the engineering characteristics of Shenzhen soft soil. Nevertheless, the results of these studies, which involved the rheological properties and engineering application of Shenzhen mucky soft soil, were hardly reported and relevant research still needs to progress. The present study uses previous research findings to conduct rheological tests on the mucky soft soil of the No.1 deep foundation pit of the Shenzhen Bay Scientific Ecological Garden and builds a rheological model of the Shenzhen mucky soft soil. The model parameters are then determined based on the test results to provide a reference for the selection of an appropriate support solution and to evaluate the time-space effect of deep foundation pit deformation.

\section{Rheological Tests on Mucky Soft Soil}

\subsection{Nature of soil sample}

The mucky soft soil samples are taken from the No. 1 deep foundation pit of the Shenzhen Bay Scientific Ecological Garden. Three mucky soft soil samples are taken from the upper, middle, and lower part of the pit according to the practical stratum status and the corresponding confining pressures is $100 \mathrm{kPa}, 200 \mathrm{kPa}$, and $250 \mathrm{kPa}$ respectively. The soil sample is ash black and brackish. For the material composition, soil grains smaller than $0.005 \mathrm{~mm}$ account for $48 \%$ of Shenzhen mucky soft soil, of which illites and chlorites with strong hydrophilia are the main components, and the organic content reaches $1.95 \%$. The gelatinized soil with surface activity and glutinousness has high moisture content and a high plasticity index so that it shows a rheological effect under constant load effects. This soil has a general sensitivity between 5 to 8 , and its saturation $\mathrm{Sr}$ is greater than $98 \%$. Its basic physical mechanical indexes are shown in Table 1. Shenzhen mucky soft oil has low strength, high compressibility and sensitivity, poor permeability, and other engineering properties

Tab.1. Basic physical mechanical indexes of Shenzhen mucky soft oil

\begin{tabular}{|c|c|c|c|c|c|c|c|c|c|c|}
\hline No. & Burial depth & Density & $\begin{array}{c}\text { Moisture } \\
\text { content }\end{array}$ & $\begin{array}{c}\text { Specific } \\
\text { gravity } \\
\text { of soil } \\
\text { grain } \\
\text { G }\end{array}$ & $\begin{array}{c}\text { Void } \\
\text { ratio } e\end{array}$ & $\begin{array}{c}\text { Plasticity } \\
\text { index } I_{P}\end{array}$ & $\begin{array}{c}\text { Compression } \\
\operatorname{modulus} E_{s}\end{array}$ & $\begin{array}{c}\text { Cohesion } \\
c\end{array}$ & $\begin{array}{c}\text { Friction } \\
\text { angle } \\
\varphi\end{array}$ & $\begin{array}{c}\text { Permeabilit } \\
\text { y coefficient } \\
k\end{array}$ \\
\hline & $\mathbf{m}$ & $\mathrm{g} / \mathrm{cm}^{3}$ & $\%$ & & & & MPa & $\mathbf{k P a}$ & $\circ$ & $\mathrm{cm} / \mathrm{s}$ \\
\hline 1 & $5.6 \sim 5.9$ & 1.71 & 53.3 & 2.71 & 1.429 & 19.6 & 1.21 & 11.3 & 12.1 & $2.0 \mathrm{E}-7$ \\
\hline 2 & $11.0 \sim 11.3$ & 1.74 & 40.3 & 2.73 & 1.201 & 15.8 & 2.35 & 17 & 11.5 & $2.8 \mathrm{E}-7$ \\
\hline 3 & $13.4 \sim 13.7$ & 1.82 & 39.6 & 2.73 & 1.094 & 16.3 & 4.56 & 13.1 & 12.9 & $5.0 \mathrm{E}-7$ \\
\hline
\end{tabular}

\subsection{Strength test}

A TSZ-6A strain control triaxial compression apparatus from Nanjing Soil Instrument Co., LTD is employed in the strength test. Six remodeled samples are prepared before the test, of which, three for strength tests and three for rheological tests. The diameter and height of the sample soil is $39.1 \mathrm{~mm}$ and $80.0 \mathrm{~mm}$ respectively. The samples are saturated under $140 \mathrm{kPa}$ confining pressure and $110 \mathrm{kPa}$ back pressure.

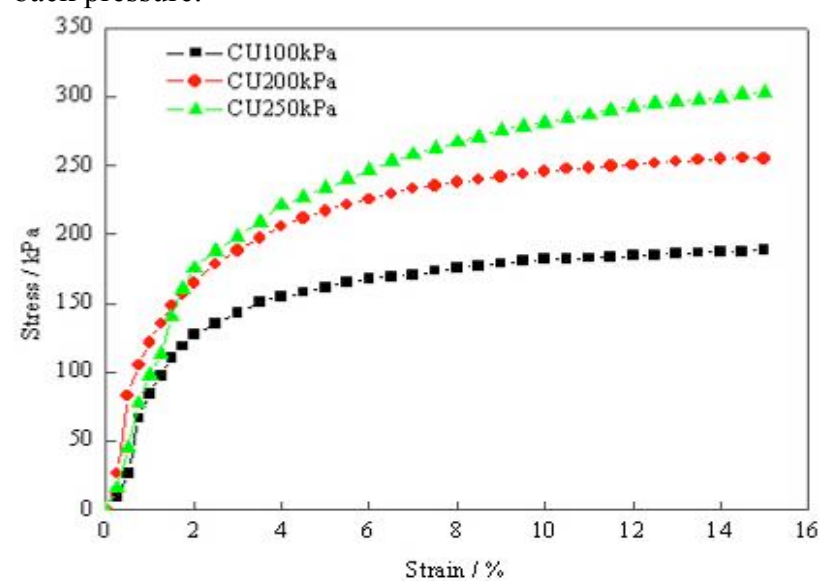

A series of triaxial consolidated-undrained shear tests are conducted in the strength test under the confining pressures of 100,200 , and $250 \mathrm{kPa}$. The test loading rate is 0.08 $\mathrm{mm} / \mathrm{min}$. The stress-strain curve of these triaxial consolidated-undrained shear tests is shown in Figure 1.

According to the Standard for Soil Test Method, the stress whose corresponding strain of $12 \%$ is regarded as the shear strength of the sample soils. Thus the shear strength of the samples under confining pressures of 100, 200, and 250 $\mathrm{kPa}$ are $q_{1}=188 \mathrm{kPa}, q_{2}=254 \mathrm{kPa}$, and $q_{3}=311 \mathrm{kPa}$, respectively.

\subsection{Experimental apparatus for the rheological test of mucky soft soil}

Regular triaxial apparatus are strain controlled, and the stress control triaxial compression apparatus can be refitted from the TSZ-6A strain control triaxial compression apparatus (Figure 2). The refitted apparatus changes the former axial strain-controlled loading system into a weight-controlled stress loading system. It also retains the confining/back pressure, pore pressure, volume change, and displacement measurement systems of the former triaxial apparatus.

Fig. 1. Strengths under different confining pressures 


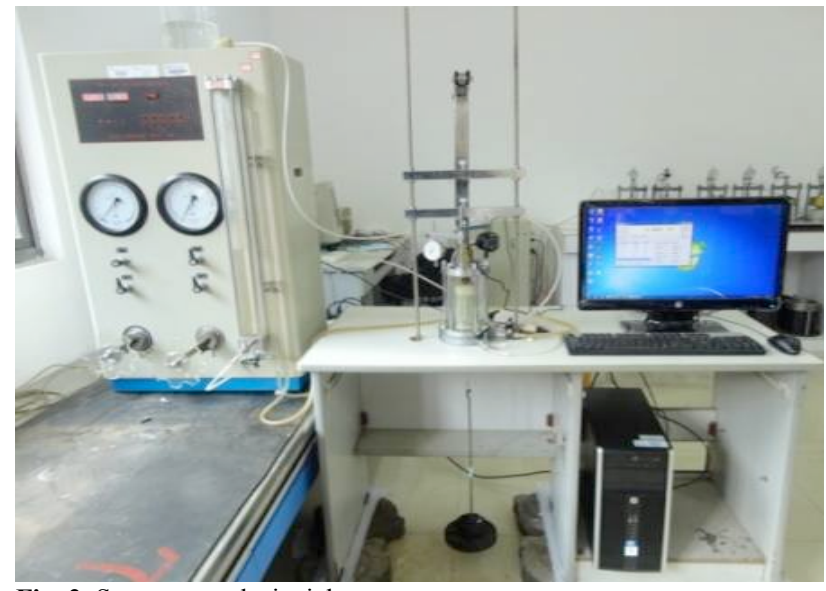

Fig. 2. Stress control triaxial apparatus

\subsection{Rheological test procedure}

(1). Determination of the rheological experimental loading levels [17]: Shear strength (deviator stress $q_{i}$ ) is generally used to determine the loading levels in rheological experiment. The load of each level is $q_{i}=q / n(n=5$ to $8)$. The loading levels under different confining pressures are listed in Table 2.

Tab.2. Loading level under different confining pressures

\begin{tabular}{cc}
\hline$\sigma_{3} / \mathrm{kPa}$ & Deviator stress $q_{i}$ \\
\hline 100 & $30 \rightarrow 60 \rightarrow 90 \rightarrow 120 \rightarrow 150 \rightarrow 180 \quad$ (failure) \\
200 & $40 \rightarrow 80 \rightarrow 120 \rightarrow 160 \rightarrow 200 \rightarrow 240 \quad$ (failure) \\
250 & $50 \rightarrow 100 \rightarrow 150 \rightarrow 200 \rightarrow 250 \rightarrow 300 \quad$ (failure) \\
\hline
\end{tabular}

(2). Sample saturation: Sample saturation can be achieved with three ways in a laboratory test by vacuum pumping saturation, hydraulic saturation, and back pressure saturation. Given the high sensitivity and poor permeability of mucky soft soil, the effect achieved by vacuum pumping and hydraulic saturation is unsatisfactory. So this study adopts the back pressure saturation method. Results show that the rheological test samples can be saturated under both $140 \mathrm{kPa}$ confining pressure and $110 \mathrm{kPa}$ back pressure.

(3). Sample drainage consolidation: Confining pressure at 100,200 , and $250 \mathrm{kPa}$ is applied to the three rheological samples. The samples are then drained and consolidated for $24 \mathrm{~h}$ under the three different confining pressures.

(4). Stepwise loading: The drain valve of the triaxial apparatus is closed during the test, and the deviator stress $q_{i}$ is applied step by step. The vertical deformation value of the samples under different levels of deviator stress is measured. If the vertical deformation value is less than $0.01 \mathrm{~mm}$ under a certain degree of deviator stress in $24 \mathrm{~h}$, then the next load level will be applied. The loading continues in this manner until the sample fails. The practical duration of each loading level is $7 \mathrm{~d}$.

(5). Data processing: The test is held based on stepwise loading and the stepwise loading rheological data processing proposed by Chen [18] is employed to acquire the rheological curves under the constant loading

\section{Results of the Rheological Test of Mucky Soft Soil}

\subsection{Rheological curve}

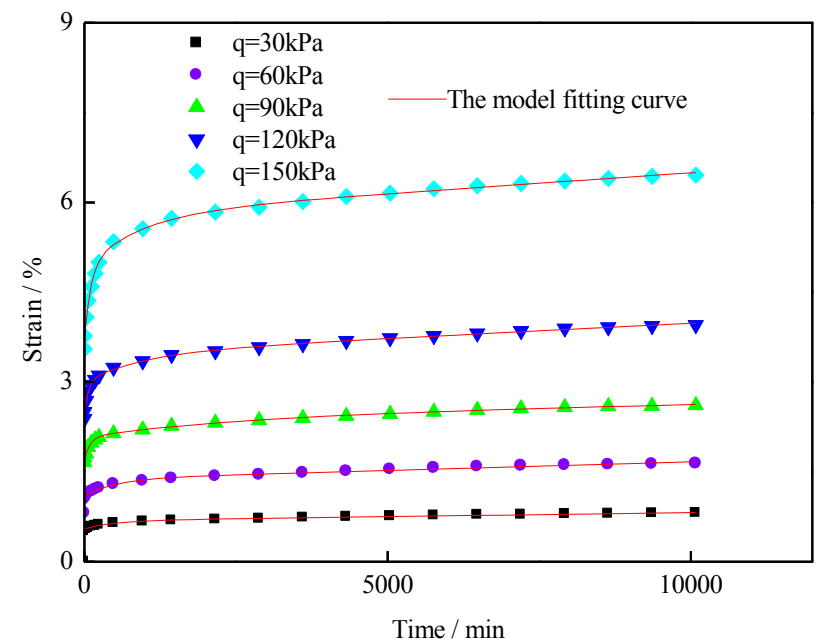

a) $100 \mathrm{kPa}$ confining pressure

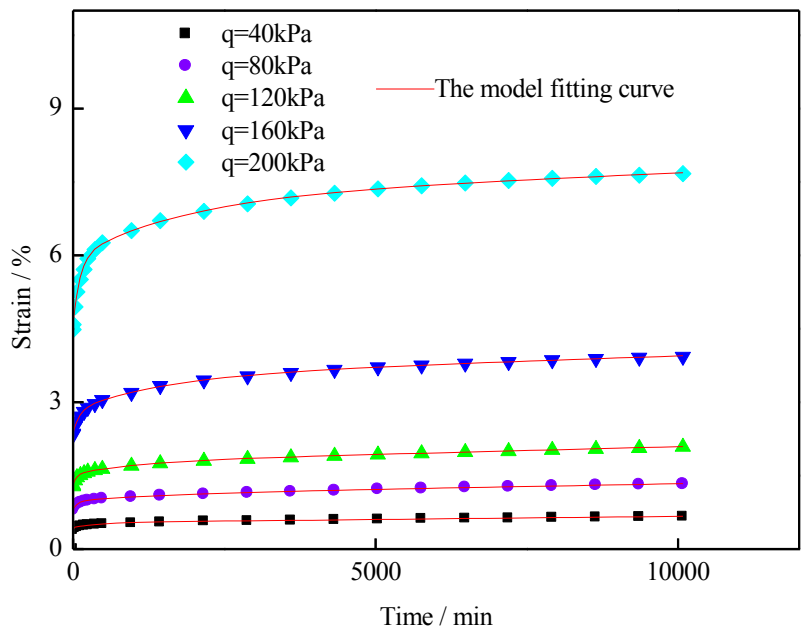

b) $200 \mathrm{kPa}$ confining pressure

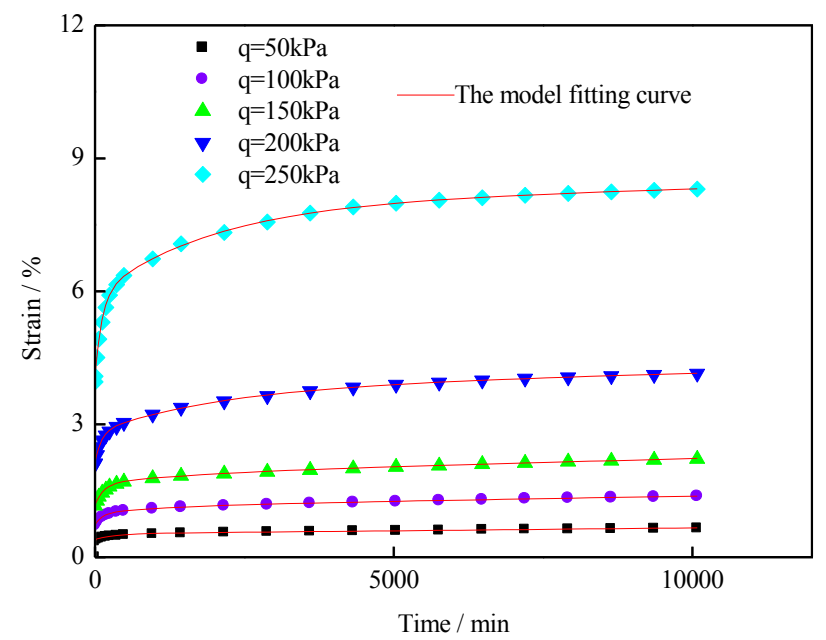

c) $300 \mathrm{kPa}$ confining pressure

Fig. 3. Mucky soft soil strain-time curve

Figure 3 shows the strain-time curve of mucky soft soil under different levels of loading and confining pressures of 
100,200 , and $250 \mathrm{kPa}$. This curve shows that Shenzhen mucky soft soil has the following rheological properties:

(1). Under different deviator stress $q_{i}$, the deformation of mucky soft soil consists of instant elastic, attenuation rheological, and stable rheological deformation.

(2). When the deviator stress $q_{i}$ is low, the rheological rate decreases and tends to zero. The rheological effect weakens and the rheological deformation tends to stabilize along with time. The rheological curve is attenuational.

(3). When the deviator stress $q_{i}$ is relatively high, the instant elastic deformation of the samples increases and the rheological rate gradually decreases to a constant value. The time required becomes longer before the rheological deformation stabilization is obtained. The rheological curve is stationary.

(4). When the deviator stress $q_{i}$ is near the failure load $q_{u}$, destructive rheology occurs, whcih is transitory with the duration of dozens to hundreds of minutes.

(5). Compared with a low deviator stress $q_{i}$, rheological deformation is more remarkable and takes a longer time under a higher deviator stress $q_{i}$. This finding indicates that the rheological property of mucky soft soil is closely related to the deviator stress $q_{i}$.

\subsection{Stress-strain isochronous curve of rheological deformation}

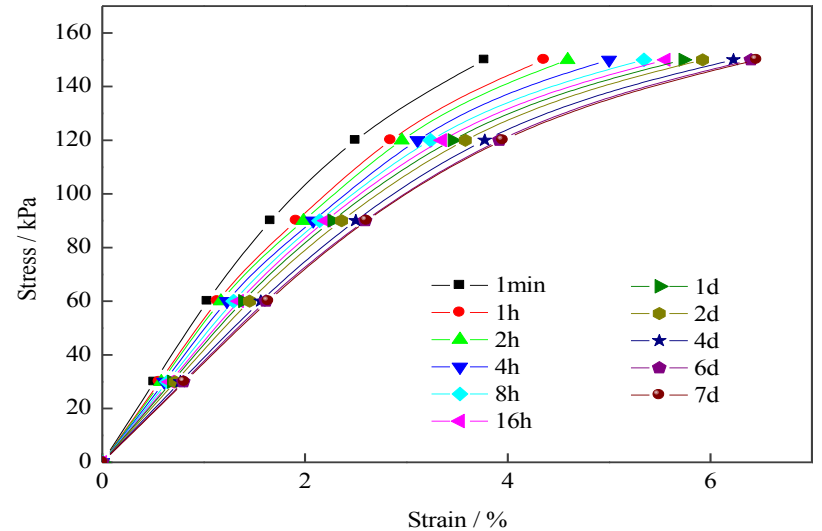

a) $100 \mathrm{kPa}$ confining pressure

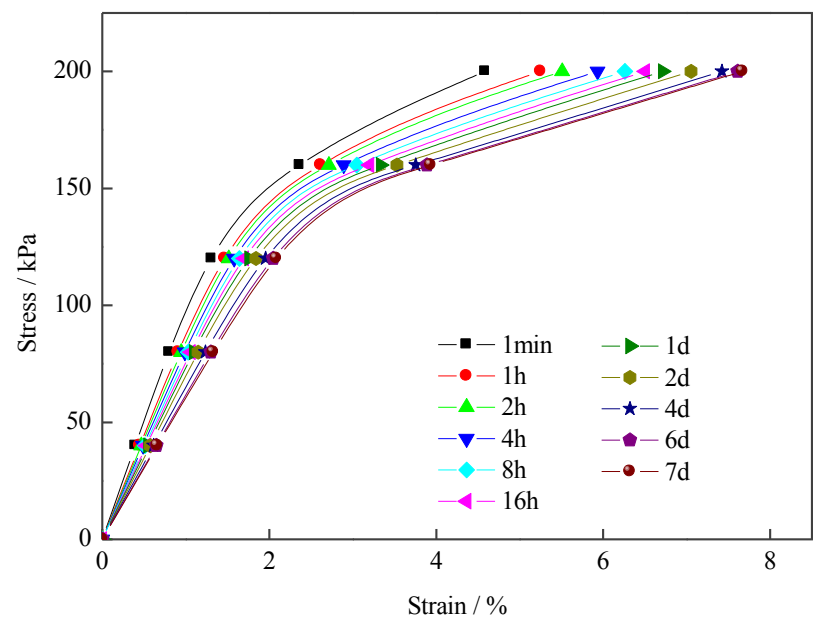

b) $200 \mathrm{kPa}$ confining pressure

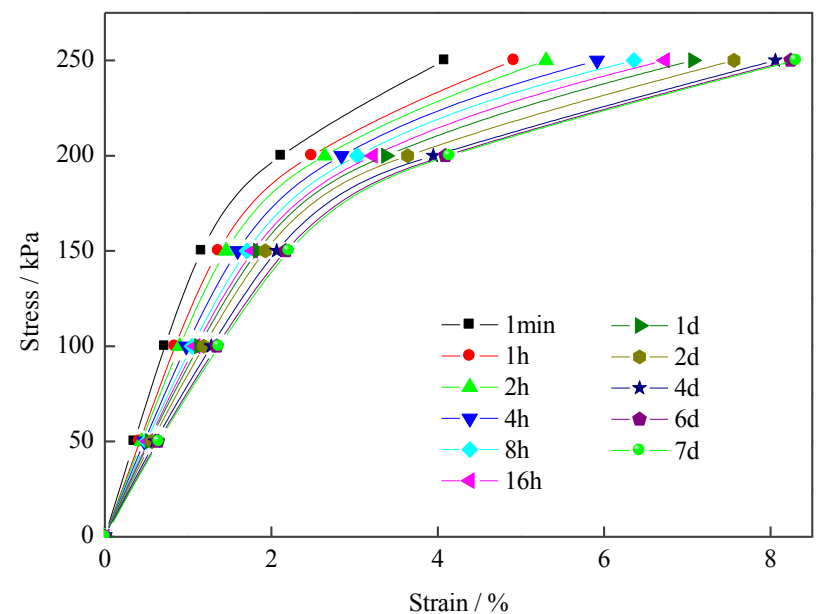

c) $300 \mathrm{kPa}$ confining pressure

Fig. 4. Stress-strain isochronous curve

Figure 4 shows the stress-strain isochronous curve of rheological deformation under the 100,200 , and $250 \mathrm{kPa}$ confining pressures. This curve shows that Shenzhen mucky soft soil has the following rheological properties:

(1). The stress-strain isochronous curve is different at different times. When the deviator stress $q_{i}$ is low, the stress-strain isochronous curve is approximately a straight line, and the mucky soft soil shows linear viscoelasticity. When the deviator stress $q_{i}$ is relatively high, the stressstrain isochronous curve moves closer to the strain axis $\varepsilon$. The higher the deviator stress $q_{i}$ is, the further the stressstrain isochronous curve swerves off a straight line. This phenomenon indicates that mucky soft soil tends to have nonlinear viscoelastic plasticity, which becomes more and more obvious with the increase of deviator stress $q_{i}$.

(2). The stress-strain isochronous curve swerves further off a straight line with time, indicating that the nonlinear degree of Shenzhen mucky soft soil increases with time.

(3). Under various confining pressures, yield stress points (i.e., inflection points) can be clearly seen on the stressstrain isochronous curve. When the deviator stress $q_{i}$ is below the yield stress, the stress-strain isochronous curve is roughly a straight line. When the deviator stress $q_{i}$ is above the yield stress, the stress-strain isochronous curve deviates from linearity, which manifests as soil softening.

\subsection{Pore water pressure-time curve}

Figure 5 shows the pore water pressure-time curve of Shenzhen mucky soft soil under the confining pressures 100 , 200 , and $250 \mathrm{kPa}$ respectively. The curve shows that the pore water pressure-time of Shenzhen mucky soft soil follows much of the same variation rule under different confining pressures. The pore water pressure rises to a stabilization stage within a very short time (usually $12 \mathrm{~h}$ ) under each level of deviator stress and undergoes a slight variation because of the ongoing rheology. 


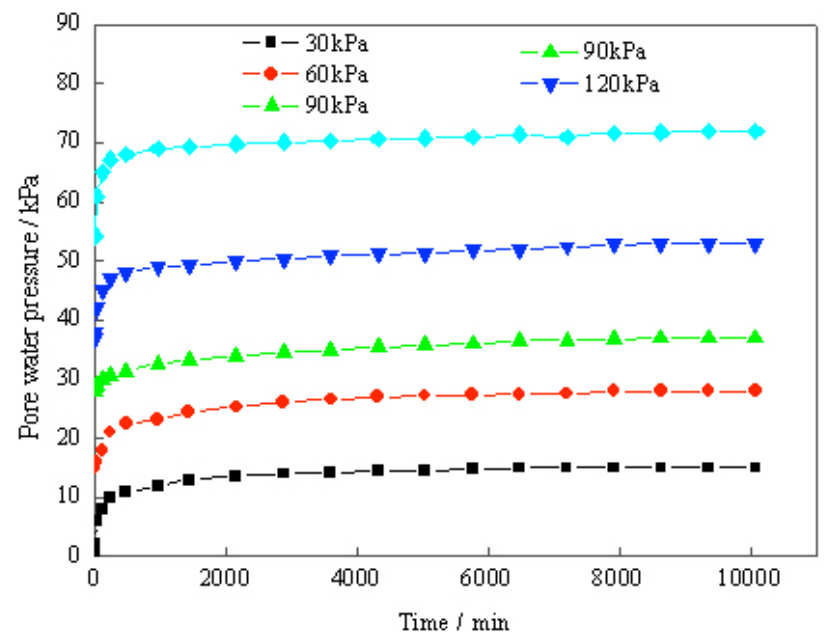

a) $100 \mathrm{kPa}$ confining pressure

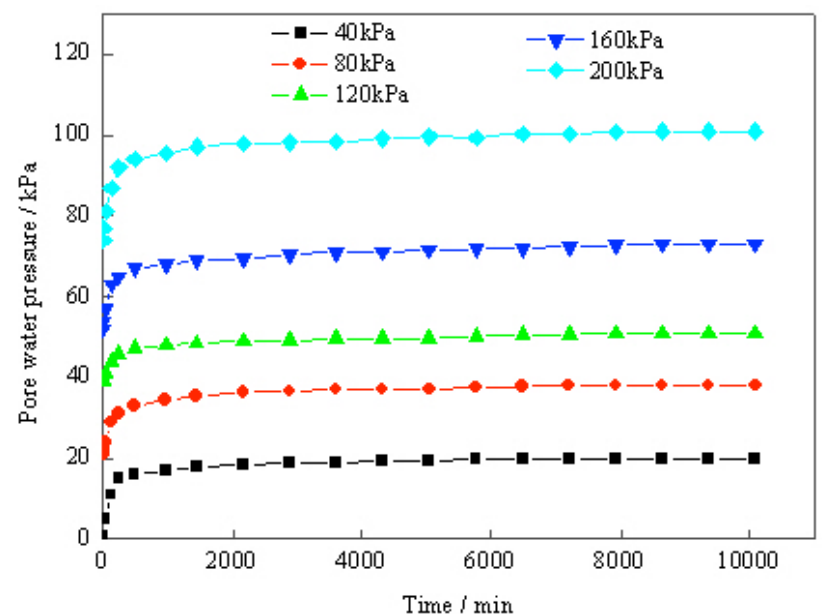

b) $200 \mathrm{kPa}$ confining pressure

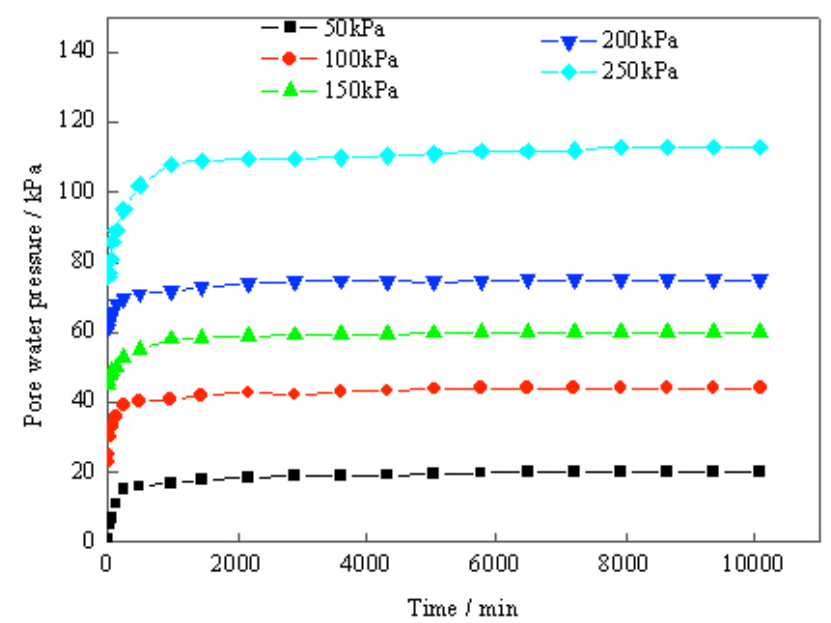

(c) $300 \mathrm{kPa}$ confining pressure

Fig. 5. Pore water pressure-time curve

The variation in pore water pressure of Shenzhen mucky soft soil during rheology is mainly caused by the viscosity effect resulting from the contact between soft-soil grains. The rheology of soft soil refers to the process where soil grain skeletons constantly change their positions to adapt to external force variations. The total sample volume remains unchanged under undrained conditions because water is considered as incompressible. Some of the effective stress of soil skeletons is transferred to the water, leading to the increase in pore water pressure. The increase in pore water pressure and decrease in soft-soil effective stress softens some structural connections between soil grains and prolongs the rheological time. Therefore, the drainage performance should be improved to its maximum possibility extent to decrease the soft-soil rheological deformation.

\section{Rheological Constitutive Model of Shenzhen Mucky Soft Soil}

\subsection{Model summary}

Just as a soil constitutive model is significant to soil mechanics, the building of a soft-soil rheological constitutive model is of great importance to the apply the results of rheological test to practical engineering $\mathrm{A}$ constitutive model must fully reflect the physical and mechanical properties of the material and its internal structure so as to accurately describe the relationship among stress, stain, and time. In general, soft-soil rheological constitutive models can be divided into empirical and component models. An empirical model is a function based on soft-soil rheological test results.. Various empirical models can be obtained from different materials and stress conditions. Given that an empirical model is an model obtained when material is under specific conditions, the application condition is limited and lack theoretical basis. An empirical model can reflect the apparent characteristics of the rheology of soft soil, but it can never show the internal characteristics or mechanisms.

Thus, a component model with an intuitive concept and definite physical meaning is more often used to build the soft-soil rheological constitutive model. Component model theory adopts basic components such as "spring," "dashpot," and "friction element" to simulate a material's elasticity, viscosity, and plasticity. These basic components are combined to build the rheological model of the soft-soil material. A component model can comprehensively reflect the rheological mechanical properties of the material. Its parameters can also be applied to the analysis of a finite element model in engineering so as to enhance the close combination of rheological property research of soft-soil and engineering application, which is exactly the purpose of the theoretical research on soft-soil rheological property.

\subsection{Six-component extended burgers model}

Burgers model is a constitutive model that describes soft-soil rheological properties. This model is made up of the Kelvin and Maxwell models in series as shown in Figure. 6. The constitutive equation is as follows:

$\sigma+\left(\frac{\eta_{\mathrm{K} 1}+\eta_{\mathrm{H}}}{E_{\mathrm{K} 1}}+\frac{\eta_{\mathrm{H}}}{E_{\mathrm{H}}}\right) \dot{\sigma}+\frac{\eta_{\mathrm{K} 1} \eta_{\mathrm{H}}}{E_{\mathrm{K} 1} E_{\mathrm{H}}} \ddot{\sigma}=$

$\eta_{\mathrm{H}} \dot{\varepsilon}+\frac{\eta_{\mathrm{K} 1} \eta_{\mathrm{H}}}{E_{\mathrm{K} 1}} \ddot{\varepsilon}$

Where, $E_{\mathrm{H}}, \eta_{\mathrm{H}}, E_{\mathrm{K} 1}$, and $\eta_{\mathrm{K} 1}$ are the elasticity modulus and coefficient of viscosity of Maxwell and Kelvin respectively.

The deviator stress $q=q_{0}$ is set as a constant. It is then substituted into Formula (1) to obtain the rheological equation. 
$\varepsilon(t)=\frac{q_{0}}{E_{\mathrm{H}}}+\frac{q_{0}}{\eta_{\mathrm{H}}} t+\frac{q_{0}}{E_{\mathrm{K} 1}}\left(1-e^{-E_{\mathrm{K} 1} t / \eta_{\mathrm{K} 1}}\right)$

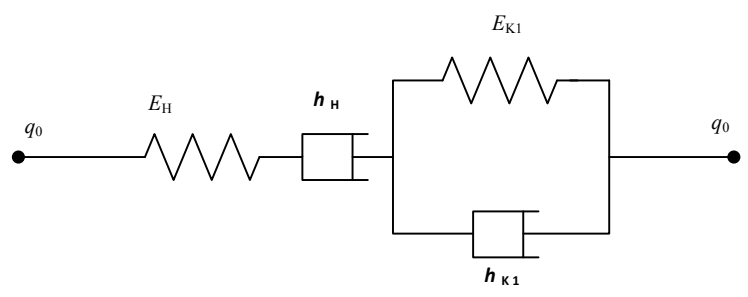

Fig. 6. Components of the Burgers model

In the Burgers model, $q_{0} / E_{\mathrm{H}}$ is the instant elastic deformation during the rheology process, $q_{0}\left(1-e^{-E_{\mathrm{K} 1} t / \eta_{\mathrm{K} 1}}\right) / E_{\mathrm{K} 1}$ is the attenuation rheological deformation, and $q_{0} t / \eta_{\mathrm{H}}$ is the stable rheological deformation.

Though, the feature of the Burgers model indicates that it can generally describe the shear rheological properties obtained from the triaxial consolidated-undrained shear rheology test of Shenzhen mucky soft soil, the fitting of the Burgers model is not rational enough in certain details resulting from parameter fitting, which is shown in the rising exponent form of the rheological curve that the curve has a small curvature and an unsatisfactory agreement between the fitted and rheological test curves. Therefore, N-1 Kelvin models are connected in series to the Burgers model to obtain the extended Burgers model based on the concept of the generalized model. The rheology rules reflected by the extended Burgers model and the original Burgers model are similar. The difference is that the extended Burgers model can simulate the test curve more accurately on the basis of empirical data and can better describe the rheological properties of Shenzhen mucky soft soil. Theoretically, the larger the $\mathrm{N}$ or number of Kelvin models are connected in series, the more accurate the newly built model can reflect the rheological properties. However, the model parameters also increase with the rise in $\mathrm{N}$, which is of much inconvenience to apply the relevant parameters to practical engineering. A Kelvin model is added to the Burgers model to consider both the accuracy of the model and the feasibility of model application. Thus, a six-component extended Burgers model is built (Figure 7) to simulate the rheological properties of Shenzhen mucky soft soil. The rheological equation of the six-component extended Burgers model is as follows:

$$
\begin{aligned}
& \varepsilon(t)=\frac{q_{0}}{E_{\mathrm{H}}}+\frac{q_{0}}{\eta_{\mathrm{H}}} t+\frac{q_{0}}{E_{\mathrm{K} 1}}\left(1-e^{-E_{\mathrm{K} 1} t / \eta_{\mathrm{K} 1}}\right) \\
& +\frac{q_{0}}{E_{\mathrm{K} 2}}\left(1-e^{-E_{\mathrm{K} 2} t / \eta_{\mathrm{K} 2}}\right)
\end{aligned}
$$

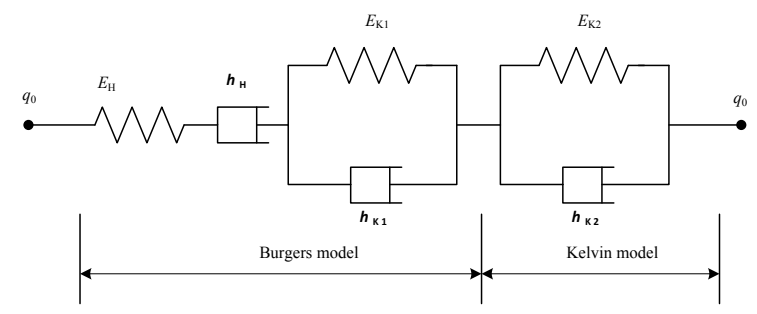

Fig. 7. Components of the extended Burgers model

Tab.3. Parameters of the extended Burgers model of Shenzhen mucky soft soil

\begin{tabular}{rrrrrrrrr}
\hline$\sigma_{3} / \mathrm{kPa}$ & $q_{i} / \mathrm{kPa}$ & $E_{\mathrm{H}} / \mathrm{kPa}$ & $\eta_{\mathrm{H}} / \mathrm{kPa} . \mathrm{h}$ & $E_{\mathrm{K} 1} / \mathrm{kPa}$ & $\eta_{\mathrm{K} 1} / \mathrm{kPa} . \mathrm{h}$ & $E_{\mathrm{K} 2} / \mathrm{kPa}$ & $\eta_{\mathrm{K} 2} / \mathrm{kPa} . \mathrm{h}$ & $\begin{array}{r}\text { Correlation } \\
\text { Coefficient } R\end{array}$ \\
\hline & 30 & 300.000 & 35767.225 & 67.057 & 0.441 & 222.692 & 1840.815 & 0.9987 \\
& 60 & 73.945 & 35159.669 & 213.601 & 1859.853 & 207.843 & 2.260 & 0.9967 \\
100 & 90 & 52.905 & 67463.151 & 273.248 & 11437.678 & 239.112 & 371.206 & 0.9987 \\
& 120 & 49.084 & 39454.838 & 215.525 & 217.680 & 253.566 & 4050.557 & 0.9990 \\
& 150 & 40.698 & 36041.499 & 122.098 & 211.276 & 169.259 & 2604.791 & 0.9988 \\
\hline & 40 & 400.000 & 51632.330 & 119.584 & 0.915 & 390.141 & 2724.960 & 0.9980 \\
& 80 & 99.729 & 60141.399 & 622.580 & 17301.198 & 443.540 & 613.917 & 0.9993 \\
& 120 & 92.448 & 62967.274 & 528.333 & 497.282 & 484.154 & 8718.227 & 0.9997 \\
& 160 & 67.696 & 63717.879 & 229.302 & 5770.491 & 343.592 & 617.768 & 0.9994 \\
& 200 & 43.855 & 67232.437 & 143.948 & 275.448 & 161.147 & 5025.100 & 0.9996 \\
\hline & 50 & 500.000 & 63192.450 & 168.990 & 1.421 & 385.037 & 2145.541 & 0.9980 \\
& 100 & 138.523 & 74370.692 & 357.979 & 803.008 & 670.414 & 17277.977 & 0.9998 \\
& 150 & 128.220 & 73332.265 & 665.941 & 20458.808 & 308.541 & 756.532 & 0.9997 \\
& 200 & 94.200 & 96568.207 & 289.633 & 516.400 & 200.854 & 7020.473 & 0.9997 \\
& 250 & 61.978 & 117594.217 & 133.902 & 263.747 & 121.172 & 3972.521 & 0.9998 \\
\hline
\end{tabular}


The linear regression analysis method of Origin software is used for the fitting of the rheological test curve of Shenzhen soft soil to obtain the parameters of the extended Burgers model under various confining pressures and deviator stress $q_{i}$ (Table 4). The model simulation results are shown in Figure 3. The results show that the instant elastic, attenuation rheological, and stable rheological deformations of Shenzhen mucky soft soil during the rheology process can all be satisfactorily fitted. The correlation coefficient $\mathrm{R}$ is greater than 0.9960 , indicating that it is appropriate and feasible to use the six-component extended Burgers model to describe the rheological properties of Shenzhen soft soil.

\section{Conclusions}

The triaxial consolidated-undrained shear rheology test shows that Shenzhen mucky soft soil has the following rheological properties:

(1). The rheological deformations of Shenzhen mucky soft soil include instant elastic, attenuation rheological, and stable rheological deformations. The value of the deviator stress $q_{i}$ directly influences the rheological process. When $q$ is below the yield stress, the rheological property manifests as linear viscoelasticity; when $q$ is above the yield stress, the rheological property manifests as nonlinear viscoelastic plasticity. Generally, low yield stress that increases with the rise in confining pressure is roughly between 90 and $150 \mathrm{kPa}$.
(2). On the whole, the pore water pressure varies with the process of rheology. Generally, in the early loading period, the pore-water pressure rises considerably and then gradually stabilizes within $12 \mathrm{~h}$. The softening effect of the soil body is greater than the hardening effect when the deviator stress $q_{i}$ is high for the increase of pore water pressure, which result in a more significant rheological phenomenon under undrained conditions. Thus, the drainage condition in practical projects should be improved to enhance the soil body strength and decrease the rheological deformation.

(3). The six-component extended Burgers model can accurately describe the instant elastic, attenuation rheological, and stable rheological deformations with a satisfactory fitting effect. The parameters of the extended Burgers model form the foundation of the analysis on timespace effect of deformation in Shenzhen deep soft-soil foundation pits.

\section{Acknowledgements}

This work was funded by the Natural Science Foundation of China (No.41302223), the funded by Chongqing Research Program of Basic Research and Frontier Technology (cstc2013jcyjA90004), and the Research Foundation of Chongqing University of Science \& Technology (CK20 11B28, CK2014Z10 and CK2013B27).

\section{References}

1. Zhang C.S., Zhang B.Y., Jiang H.H. "On consolidation deformation properties of neritic facies silt at Shenzhen Bay", Hydrogeology and Engineering Geology, 32(3), 2005, pp. 35-37.

2. Zhang H.M., Xu Y.S., Zeng Q.L. "Deformation behavior of Shenzhen soft clay and post-construction settlement", Chinese Jounal of Geotechnical Engineering, 24(4), 2002, pp. 509-514.

3. Zhang K.C., Qiu J.J. Geotechnical engineering's theory and practice in Shenzhen area, China Architecture \& Building Press, Beijing, 2000.

4. Chen X.P., Zhu H.H., Zhang F.Z., et al. "Experimental study on time-dependent deformation of soft soil", Chinese Journal of Rock Mechanics and Engineering, 24(12), 2005, pp. 2142-2148.

5. O'Kelly B.C. "Compression and consolidation anisotropy of some soft soils", Geotechnical and Geological Engineering, 24(6), 2006, pp. $1715-1728$

6. LI J.Z., Peng F.L. "Experimental research on creep property of clay", Rock and Soil mechanics, 27(2), 2006, pp.214-218.

7. Sun J. Geotechnical Material Rheology and Its Engineering Application, China Architecture \& Building Press, Beijing, 1999.

8. Hu A., Sun B., Xie K. "Steady-state response of a saturated halfspace with an overlying dry layer subjected to a moving load", Journal of Zhejiang University: Science A, 13(1), 2012, pp. 33-43.

9. Sun L.N., Liu Y., Zhang L.M. "Analysis on deformation of foundation excavation considering of time-space effect", Applied Mechanics and Materials, v 291-294, 2013, pp. 1135-1139

10. Gnanendran C.T., Manivannan G., Lo S.C.R. "Influence of using a creep, rate, or an elastoplastic model for predicting the behaviour of embankments on soft soils", Canadian Geotechnical Journal, 43(2),2006, pp. 134-154.
11. Karim M.R., Gnanendran C.T., Lo S.C.R., et al. "Predicting the long-term performance of a wide embankment on soft soil using an elastic-viscoplastic model”, Canadian Geotechnical Journal, 47 (2), 2010, pp. 244-257.

12. Zhang W., Qian P.Y., Chen X.P., et al. "Application of rheological theory to excavation of deep foundation pit", Journal of Wuhan University of Hydraulic and Electric Engineering, 36(2), 2003, pp 92-96.

13. Gao W.H., Yang L.D., Shen P.S. "Analysis of factors on timespace effect of internal force and deformation for retaining structure of deep foundation pit under soft soil” , China Civil Engineering Journa, 34(5), 2011, pp. 90-96.

14. Bo M.W., Choa V., Wong K.S., et al. "Laboratory validation of ultra-soft soil deformation model", Geotechnical and Geological Engineering, 29 (1), 2011, pp 65-74.

15. Chen X.P., Huang G.Y., Liang Z.S. "Study on soft soil properties of the pearl river delta", Chinese Journal of Rock Mechanics and Engineering, 22(1), 2003, pp 137-141.

16. Liu W.T., Cao D.Z., Li H., et al. "Experimental study on creep behavior of marine clay in Shenzhen", Industrial Construction, 41(7), 2011, pp 74-77.

17. Xie X.Y., Li J.Z., Wang W.J., et al. "Rheological test and empirical model of Ningbo soft soil", Journal of Zhejiang University (Engineering Science), 46(1), 2012, pp. 64-71.

18. Chen Z.J. "One dimensional problems of consolidation and secondary time effects", China Civil Engineering Journal, 5 (1), 1958, pp. 1-10. 